\title{
Global Progression GvHD
}

National Cancer Institute

\section{Source}

National Cancer Institute. Global Progression GVHD. NCI Thesaurus. Code C126735.

A clinician overall severity score that has increased by 2 or more points on a 0-10 scale. 